\title{
A systematic review and meta-analysis: tailoring asthma treatment on eosinophilic markers (exhaled nitric oxide or sputum eosinophils)
}

\author{
H L Petsky, ${ }_{1,4}^{1,4}$ J Cates, ${ }^{2} \mathrm{~T}$ J Lasserson, ${ }^{2}$ A M Li, ${ }^{3}$ C Turner, ${ }^{4}$ J A Kynaston, ${ }^{5}$ \\ A B Chang ${ }^{1,6}$
}

\section{See Editorial, p 191}

- Additional material is published online only. To view this file please visit the journa online (http://throax.bmj.com/ content/67/3.toc)

${ }^{1}$ Queensland Children's Respiratory Centre and Old Children's Medical Research Institute, Royal Children's Hospital, Brisbane, Old, Australia

${ }^{2}$ Community Health Sciences, St George's, University of London, London, UK

${ }^{3}$ Department of Paediatrics, Prince of Wales Hospital, The Chinese University of Hong Kong, Shatin, Hong Kong

${ }^{4}$ The University of Queensland, School of Nursing \& Midwifery, Old, Australia

${ }^{5}$ Department of General Paediatrics, Royal Children's Hospital, Brisbane, Old, Australia

${ }^{6}$ Queensland Children's Respiratory Centre and Child Health Division, Menzies School of Health Research, Darwin, NT, Australia

\section{Correspondence to} Helen Petsky, Queensland Children's Respiratory Centre, Royal Children's Hospital, Herston, Brisbane, Queensland 4029, Australia;

helen_petsky@health.qld.gov.au

Received 22 January 2010 Accepted 29 April 2010 Published Online First 11 October 2010

\section{ABSTRACT}

Asthma severity and control can be measured both subjectively and objectively. Traditionally asthma treatments have been individualised using symptoms and spirometry/peak flow. Increasingly treatment tailored in accordance with inflammatory markers (sputum eosinophil counts or fractional exhaled nitric oxide (FeNO) data) is advocated as an alternative strategy. The objective of this review was to evaluate the efficacy of tailoring asthma interventions based on inflammatory markers (sputum analysis and FeNO) in comparison with clinical symptoms (with or without spirometry/peak flow) for asthma-related outcomes in children and adults. Cochrane Airways Group Specialised Register of Trials, the Cochrane Central Register of Controlled Trials (CENTRAL), MEDLINE, EMBASE and reference lists of articles were searched. The last searches were in February 2009. All randomised controlled comparisons of adjustment of asthma treatment based on sputum analysis or FeNO compared with traditional methods (primarily clinical symptoms and spirometry/peak flow) were selected. Results of searches were reviewed against predetermined criteria for inclusion. Relevant studies were selected, assessed and data extracted independently by at least two people. The trial authors were contacted for further information. Data were analysed as 'intervention received' and sensitivity analyses performed. Six (2 adults and 4 children/ adolescent) studies utilising FeNO and three adult studies utilising sputum eosinophils were included. These studies had a degree of clinical heterogeneity including definition of asthma exacerbations, duration of study and variations in cut-off levels for percentage of sputum eosinophils and FeNO to alter management in each study. Adults who had treatment adjusted according to sputum eosinophils had a reduced number of exacerbations compared with the control group (52 vs 77 patients with $\geq 1$ exacerbation in the study period; $p=0.0006$ ). There was no significant difference in exacerbations between groups for FeNO compared with controls. The daily dose of inhaled corticosteroids at the end of the study was decreased in adults whose treatment was based on FeNO in comparison with the control group (mean difference $-450.03 \mu \mathrm{g}, 95 \% \mathrm{Cl}$ -676.73 to $-223.34 ; p<0.0001)$. However, children who had treatment adjusted according to FeNO had an increase in their mean daily dose of inhaled corticosteroids (mean difference $140.18 \mu \mathrm{g}, 95 \% \mathrm{Cl}$ 28.94 to $251.42 ; p=0.014)$. It was concluded that tailoring of asthma treatment based on sputum
Key messages

What is the key question?

- What is the overall outcome of trials assessing the use of the sputum eosinophil counts and exhaled nitric oxide to tailor asthma treatment?

What is the key point?

- Treatment tailored using the sputum eosinophil count results in fewer asthma attacks than traditional management in adults with severe asthma; the overall findings with exhaled nitric oxide are negative but they are difficult to interpret because of differences in methodology.

Why read on?

- There has been considerable interest in inflammometry in asthma management and the benefits of sputum guided management in severe asthma are marked.

eosinophils is effective in decreasing asthma exacerbations. However, tailoring of asthma treatment based on FeNO levels has not been shown to be effective in improving asthma outcomes in children and adults. At present, there is insufficient justification to advocate the routine use of either sputum analysis (due to technical expertise required) or FeNO in everyday clinical practice.

\section{INTRODUCTION}

Monitoring tools to assist in improving asthma control and prevention of exacerbations are two key elements in asthma guidelines. ${ }^{1-3}$ There is no single outcome measure that can adequately assess asthma control. ${ }^{4}$ Subjective measures usually involve a series of questions used for clinical assessment, diary cards and quality of life ( $\mathrm{QoL}$ ) questionnaires. Traditional objective methods used to monitor (but not control) asthma include spirometry/peak flow and degree of airway hyperresponsiveness (AHR). ${ }^{5}$ Newer methods include measurement of airway inflammation such as airway cellularity in induced sputum or fractional exhaled nitric oxide (FeNO).

The inflammation in airways of people with asthma can be predominantly eosinophilic or non- 
eosinophilic (including neutrophilic). ${ }^{6}$ Irrespective of the type of airway inflammation, inhaled corticosteroids (ICS) remain the major preventer treatment to control asthma symptoms in those with asthma, other than children with mild intermittent asthma. ${ }^{3}$ However, ICS are more effective in reducing symptoms in patients with eosinophilic inflammation than those with neutrophilic inflammation. ${ }^{7}$ Thus investigations that provide objective data on eosinophilic inflammation may be helpful in reducing exacerbations and improve asthma control. Current available techniques for clinical use are assessment of sputum cellularity and FeNO. ${ }^{8}$

A systematic review evaluating the efficacy of tailoring asthma interventions based on utilising sputum eosinophils or FeNO in comparison with current strategy (reliance on clinical symptoms with or without spirometry/peak flow) will be useful to guide clinical practice. Here we combine two Cochrane reviews ${ }^{10}$ that address this question. The objective of this systematic review is to evaluate the efficacy of tailoring asthma interventions based on FeNO or sputum eosinophils in comparison with controls (clinical symptoms with or without spirometry/peak flow) for asthma-related outcomes in children and adults.

\section{METHODS}

Methods of the analysis and inclusion criteria were specified in advance and documented in protocols that are available alongside the original versions of these reviews in The Cochrane Library.

\section{Eligibility, information sources, search strategy and study selection}

We used the PRISMA guidelines, ${ }^{11}$ Cochrane collaboration methodology and software (RevMan5). We searched the Cochrane Airways Group specialised register for eligible randomised controlled trials that compared adjustment of asthma medications based on sputum eosinophils or FeNO levels in comparison with clinical symptoms (with or without spirometry/peak flow) using keywords in electronic sources (Cochrane Airways Group Specialised Register of Trials, the Cochrane Central Register of Controlled Trials (CENTRAL), Medline, EMBASE) and hand searching of references as outlined in the reviews. ${ }^{9} 10$ The latest searches were performed in February 2009. Trials that included the use of other interventions were included if all participants had equal access to such interventions.
Participant inclusion criteria were children and adults with 'classical asthma'. Exclusion criteria were: eosinophilic bronchitis, asthma related to an underlying lung disease such as bronchiectasis and chronic obstructive airway disease, or diagnostic categories such as 'cough variant asthma' and 'wheezy bronchitis' where controversies exist.

\section{Data items}

From the title, abstract or descriptors, the literature search was reviewed independently in triplicate to identify potentially relevant trials for full review. Searches of bibliographies and texts were conducted to identify additional studies. From the full text using specific criteria, two reviewers independently selected trials for inclusion. There was no disagreement, although it was planned that disagreement would have been resolved by thirdparty adjudication. We extracted information from each trial on (1) study characteristics, (2) intervention type and (3) outcomes, as described in our Cochrane reviews. 910

\section{Risk of bias}

Risk of bias for each study was assessed using the tool available in the RevMan software. Six components were assessed: (1) adequate sequence generation; (2) allocation concealment; (3) blinding; (4) incomplete outcome data addressed; (5) free of selective reporting; and (6) free of other bias. Studies included in the review underwent quality assessment and were entered into a 'risk of bias' table.

\section{Summary (outcome) measures}

Primary outcomes were the number of participants who had asthma exacerbations during follow-up. Secondary outcomes were mean difference in asthma-related outcome measures, number of participants experiencing adverse effects of the interventions and number of participants experiencing complications such as requirement for medication change. The proportions of participants and the mean clinical improvement were determined using the following hierarchy of assessment measures (ie, where two or more assessment measures are reported in the same study, the outcome measure that is listed first in the hierarchy was used);

1. Hospitalisation, acute presentations to an emergency facility for asthma.

2. Rescue courses of oral corticosteroids.

Figure 1 PRISMA flow chart.

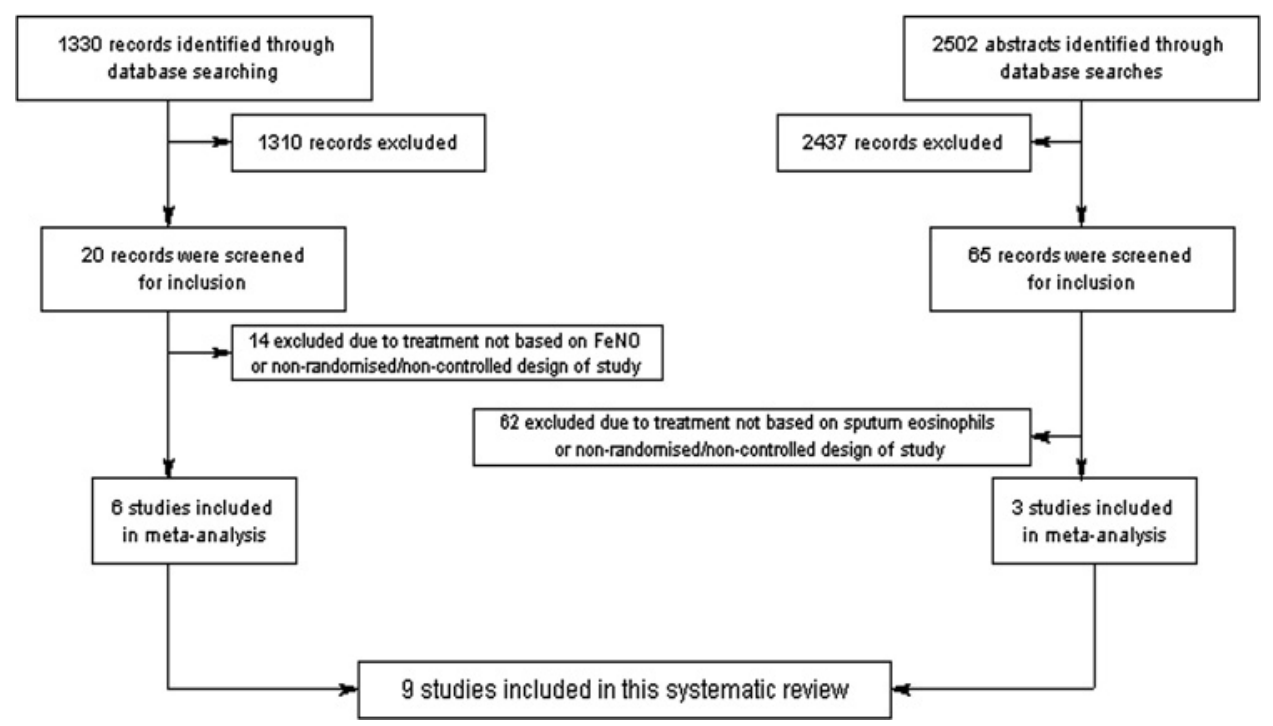




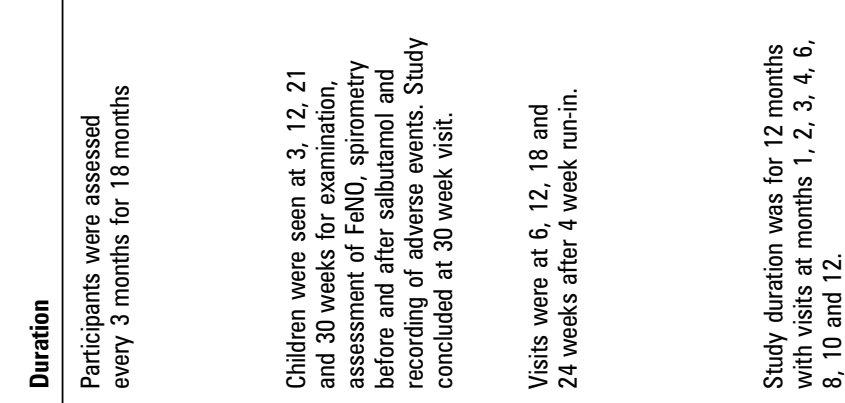

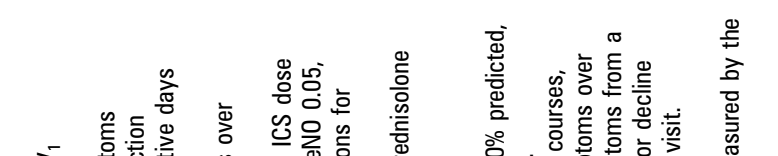

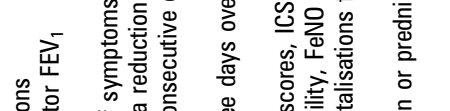

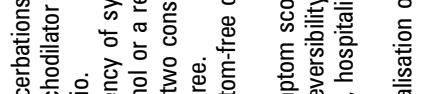

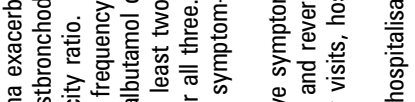

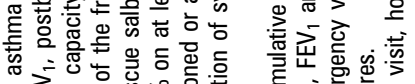

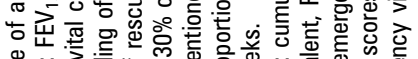

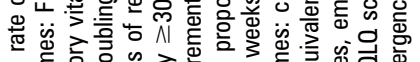

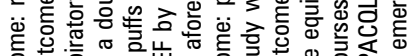

:

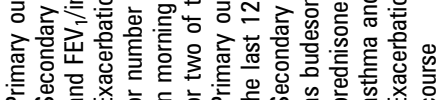

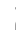

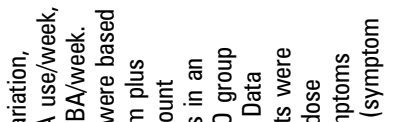

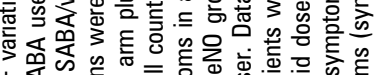

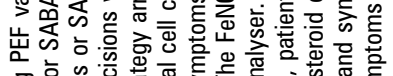

늫

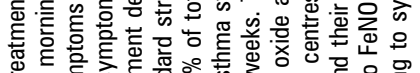

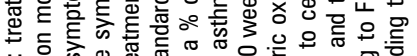

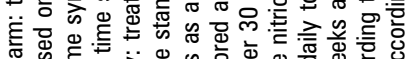

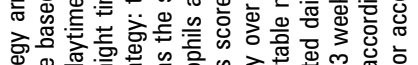

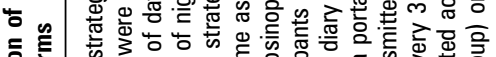

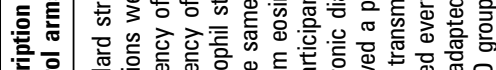

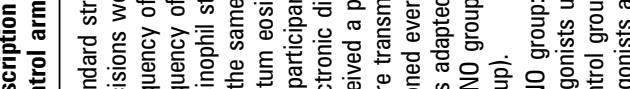

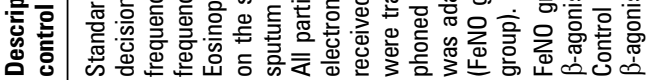
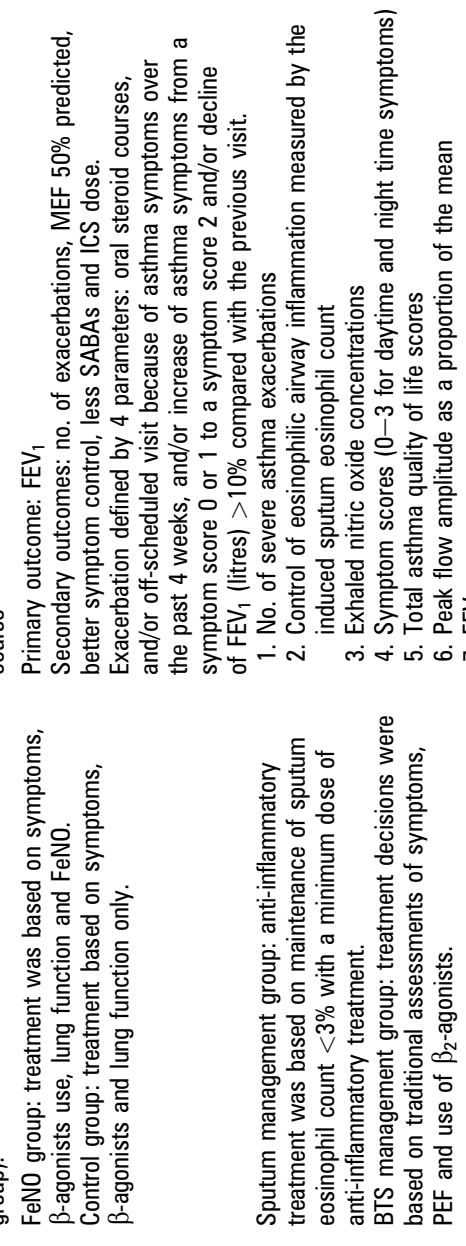

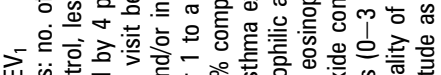

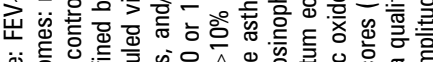

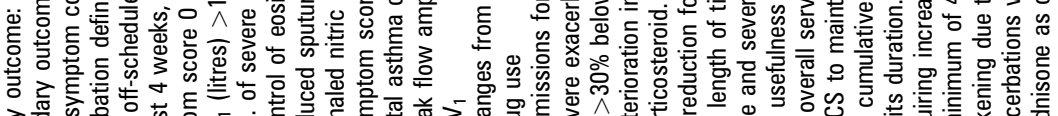

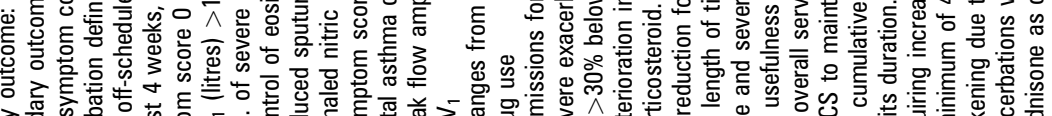

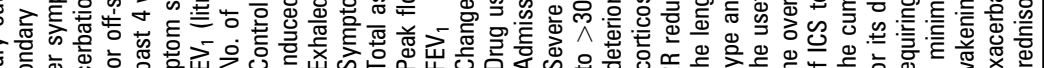

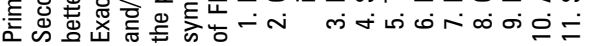

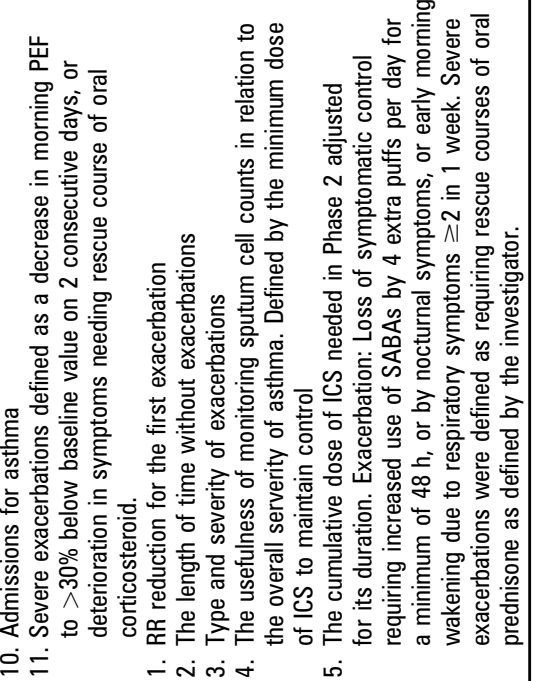

तथं

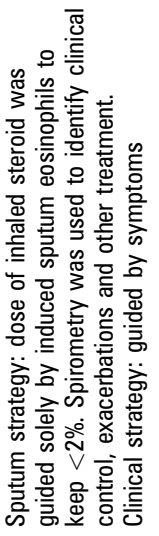

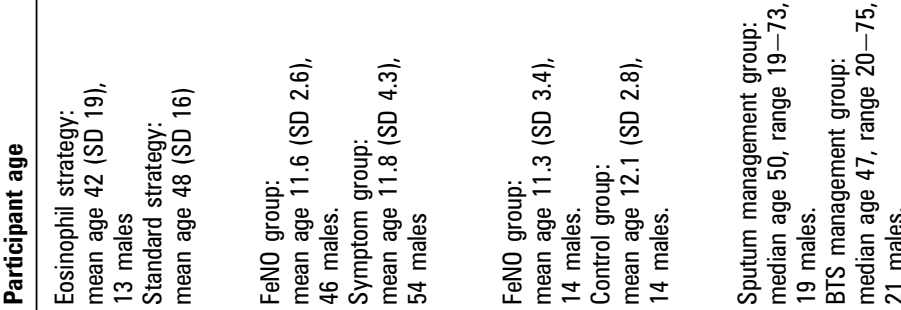

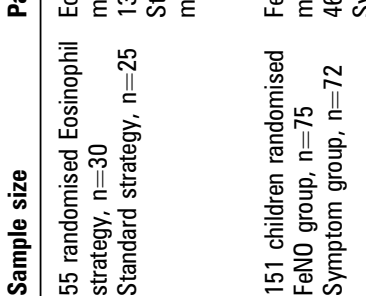

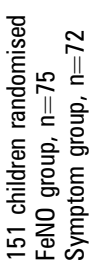
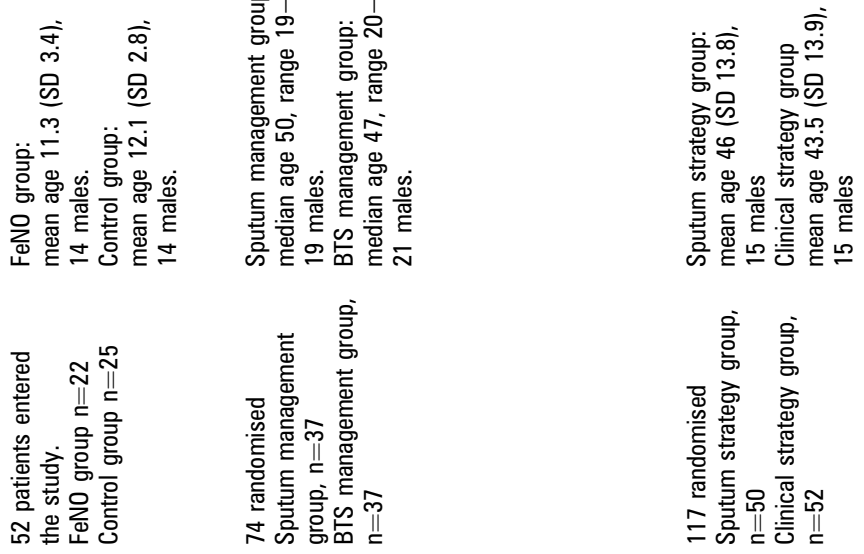

害厗总

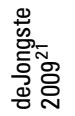

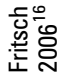

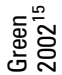




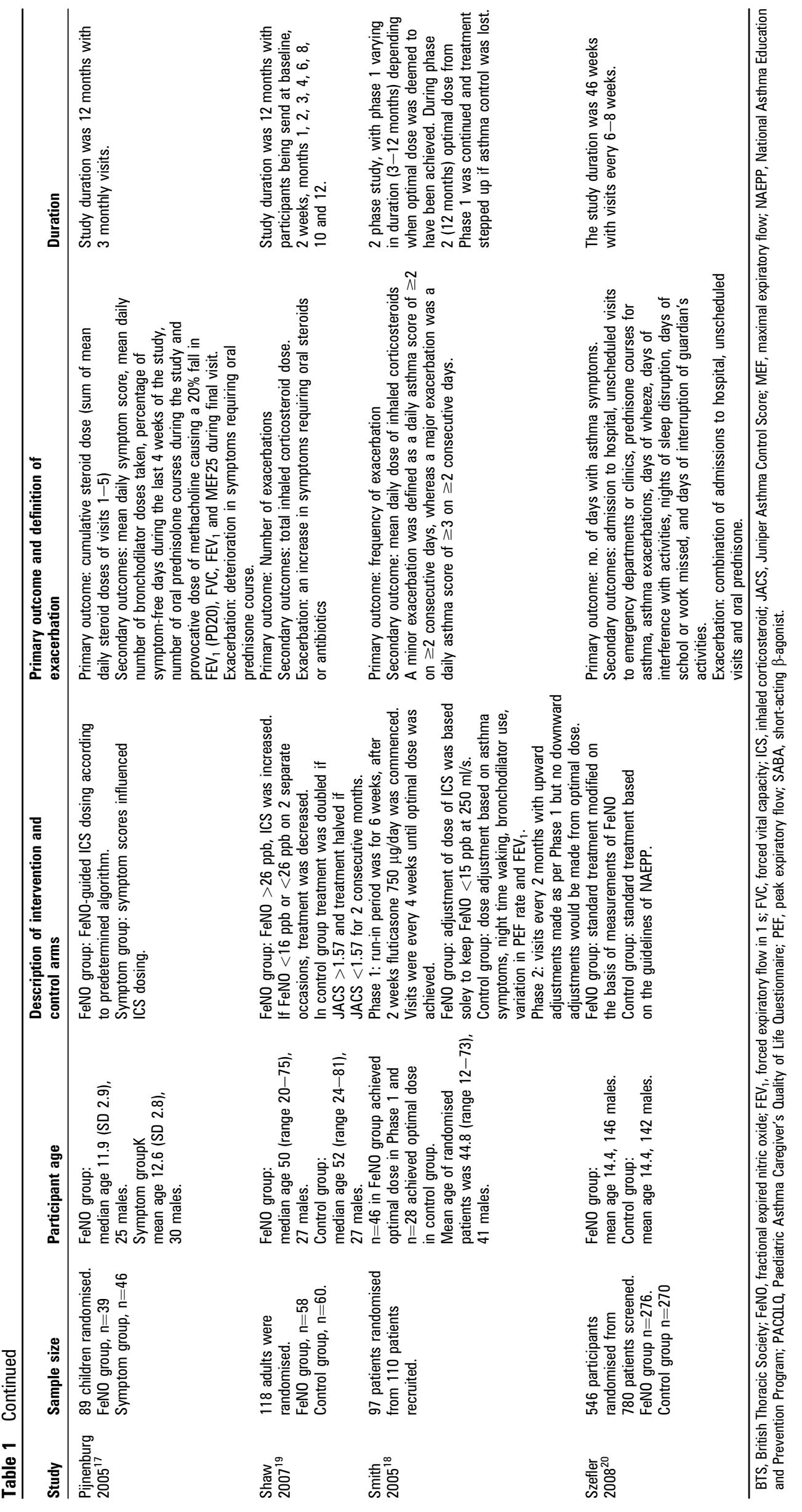


Figure 2 Number of subjects who had $\geq 1$ exacerbation over the study period (fractional exhaled nitric oxide (FeNO)).

\begin{tabular}{|c|c|c|c|c|c|c|c|}
\hline Study or Subgroup & $\begin{aligned} \text { FeNO } \\
\text { Events } T\end{aligned}$ & Total & $\begin{array}{l}\text { Contr } \\
\text { Events }\end{array}$ & $\begin{array}{l}\text { ol } \\
\text { Total }\end{array}$ & Weight & $\begin{array}{l}\text { Odds Ratio } \\
\text { M-H, Random, } 95 \% \mathrm{Cl}\end{array}$ & $\begin{array}{c}\text { Odds Ratio } \\
\text { M-H, Random, } 95 \% \mathrm{Cl}\end{array}$ \\
\hline \multicolumn{8}{|l|}{ Adults } \\
\hline $\begin{array}{l}\text { Shaw } 2007 \\
\text { Smith } 2005 \\
\text { Subtotal }(95 \% \mathrm{Cl})\end{array}$ & $\begin{array}{l}12 \\
14\end{array}$ & $\begin{array}{l}52 \\
46 \\
98\end{array}$ & $\begin{array}{l}19 \\
11\end{array}$ & $\begin{array}{l}51 \\
48 \\
99\end{array}$ & $\begin{array}{c}51.2 \% \\
48.8 \% \\
100.0 \%\end{array}$ & $\begin{array}{l}0.51[0.21,1.19] \\
1.47[0.59,3.69] \\
0.85[0.30,2.43]\end{array}$ & \\
\hline \multicolumn{8}{|c|}{$\begin{array}{l}\text { Heterogeneity: } \text { Tau }^{2}=0.36 ; \mathrm{Chi}^{2}=2.77, \mathrm{df}=1(P=0.10) ;\left.\right|^{2}=64 \% \\
\text { Test for overall effect: } Z=0.30(P=0.76)\end{array}$} \\
\hline \multicolumn{8}{|l|}{ Children } \\
\hline de Jongste 2009 & 9 & 75 & 12 & 72 & $10.9 \%$ & $0.68[0.27,1.73]$ & \\
\hline Pijnenburg 2005 & 7 & 42 & 10 & 47 & $8.3 \%$ & $0.74[0.25,2.16]$ & \\
\hline $\begin{array}{l}\text { Szefler } 2008 \\
\text { Subtotal }(95 \% \mathrm{Cl})\end{array}$ & 102 & $\begin{array}{l}276 \\
393\end{array}$ & 118 & $\begin{array}{l}270 \\
389\end{array}$ & $\begin{array}{r}80.8 \% \\
100.0 \%\end{array}$ & $\begin{array}{l}0.76[0.54,1.06] \\
0.75[0.55,1.01]\end{array}$ & \\
\hline $\begin{array}{l}\text { Total events } \\
\text { Heterogeneity: Tau }{ }^{2} \\
\text { Test for overall effect: }\end{array}$ & $\begin{aligned} & 118 \\
= & 0.00 \\
Z & =1.87\end{aligned}$ & $\begin{array}{l}\mathrm{Chi}^{2}= \\
(\mathrm{P}=\mathrm{C}\end{array}$ & $\begin{aligned} & 140 \\
&= 0.04, d \\
&0.06)\end{aligned}$ & $\mathrm{ff}=2($ & $(P=0.9$ & $8): 1^{2}=0 \%$ & \\
\hline
\end{tabular}

3. Symptomatic (QoL, Likert scale, asthma diary, visual analogue scale)-assessed by the patient (adult or child).

4. Symptomatic (QoL, Likert scale, asthma diary, visual analogue scale)-assessed by the parents/carers.

5. Symptomatic (Likert scale, visual analogue scale)-assessed by clinicians.

6. Indices of spirometry, peak flow, AHR.

7. $\beta$-Agonist used.

In addition, dose of ICS used was also analysed as a post hoc analysis.

\section{Methods of analysis}

The results from studies that met the inclusion criteria and reported any of the outcomes of interest were included in the subsequent meta-analyses. All data were double entered (HP and AC) and triple checked (CC). For the dichotomous outcome variables of each individual study, relative and absolute risk reductions were calculated using a modified intention-to-treat analysis when the outcome event is a beneficial event. When the event is non-beneficial (such as exacerbation), 'treatment received' analysis was utilised. The summary weighted RR and 95\% CI (fixed effect model) were calculated (Cochrane statistical package, RevMan 5.0). For rate ratios of common events whereby one subject may have more than one event, generic inverse variance (GIV) was utilised. The rate ratios were taken from the published papers and the standard errors were calculated from CIs or $\mathrm{p}$ values published in the papers. Number needed to treat (NNT) was calculated from the pooled OR and its $95 \%$ CI applied to a specified baseline risk using an online calculator. $^{12}$ If studies reported outcomes using different measurement scales, the standardised mean difference was estimated. Any heterogeneity between the study results was described and tested to see if it reached statistical significance using a $\chi^{2}$ test. The $95 \%$ CI estimated using a random effects model was included whenever there were concerns about statistical heterogeneity. Heterogeneity was considered significant when the $\mathrm{p}$ value is $<0.10 .{ }^{13}$ An a priori subgroup analysis was planned for adults versus children.

\section{RESULTS}

\section{Study selection and study characteristics}

The searches identified 1330 FeNO-based studies and 2502 sputum studies (figure 1). After screening 20 and 65 papers, respectively, 6 and 3 , respectively, fulfilled the inclusion criteria (figure 1) for the interventions. The nine studies ( 3 adult studies utilising sputum eosinophils, 6 studies utilising FeNO-2 adults, 4 children) involved 1299 participants, with 1231 completing.

Of the nine studies included (table 1), six were unicentre studies ${ }^{14-19}$ and three were multicentred. ${ }^{20-22}$ Four studies were in children or adolescents, ${ }^{16} 172021$ four with adult patients ${ }^{19}$ and one combining adolescents and adults. ${ }^{18}$ We classified studies into children/adolescent studies based on the mean age reported as opposed to the entry criteria. Four studies were double blind, parallel groups ${ }^{17} 20$ whereas five were single blind,

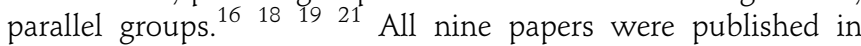
English.

There was a degree a clinical heterogeneity between studies as summarised in table 1. Most variation related to the definition of
Figure 3 Number of subject who had $\geq 1$ exacerbation over the study period (sputum eosinophils (SpEos)).

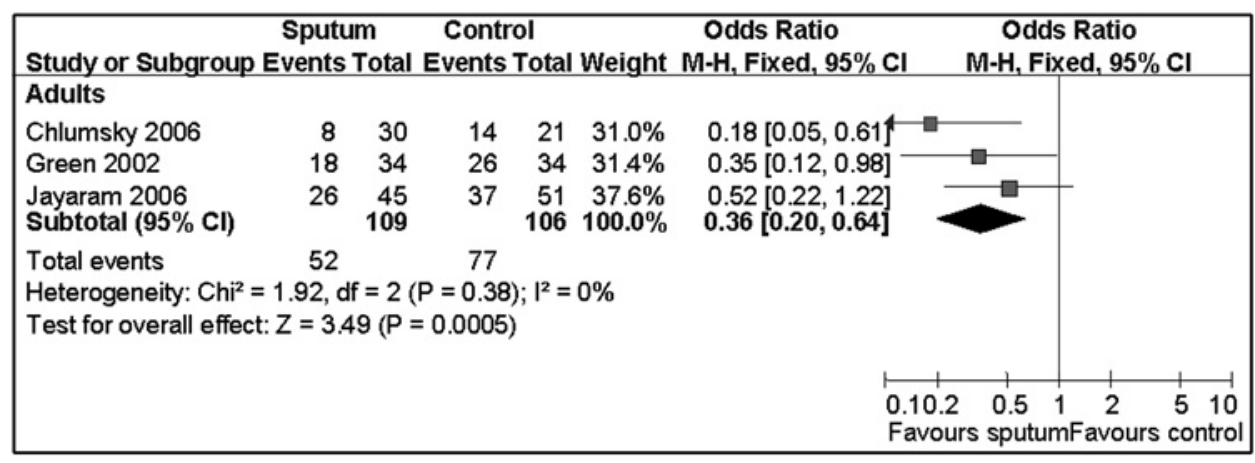


Figure 4 Inhaled corticosteroid dose at final visit (fractional exhaled nitric oxide (FeNO)).

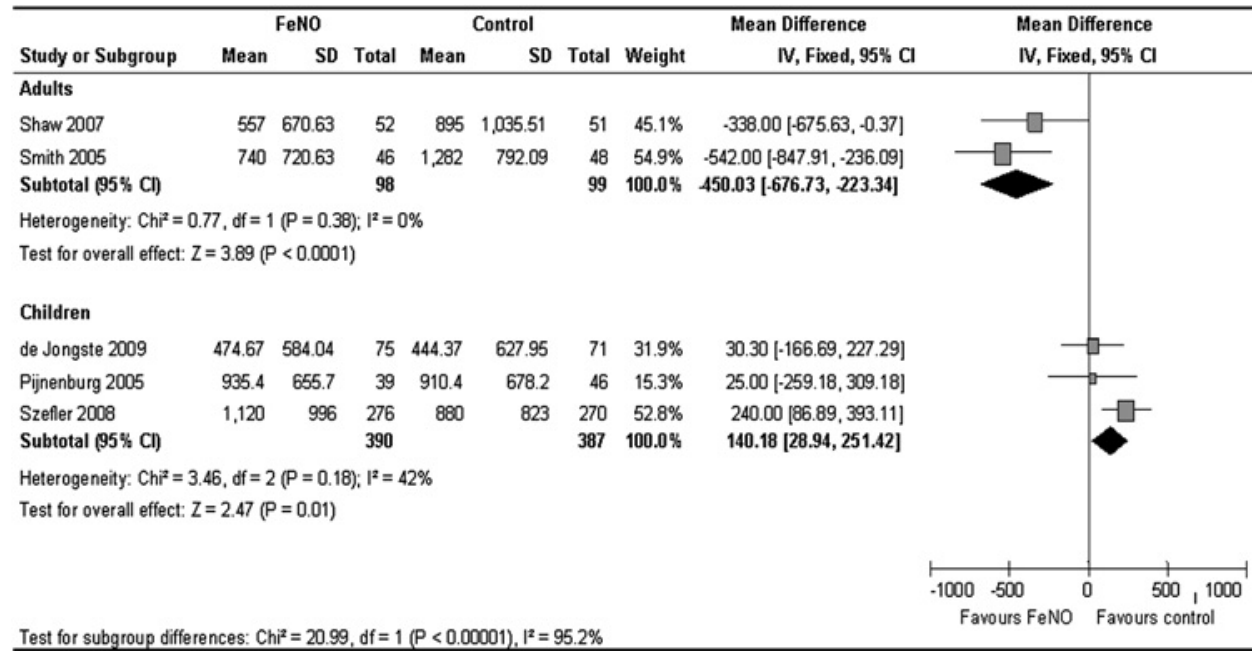

an asthma exacerbation and the cut-off utilised for adjusting treatments. Although asthma exacerbations were an outcome measure in all papers, they differed in how they were defined, ranging from unscheduled emergency visits ${ }^{21} 20$ to defining an exacerbation using diary card data. ${ }^{18}$ Although there was variation in how exacerbations were defined, all included studies uniformly managed exacerbations with rescue oral steroids. Algorithms for adjustment of medications differed between studies and the cut-off values to step-up and step-down also varied across the FeNO studies (range from $20^{162021}$ to $35^{18}$ ), and the sputum eosinophil percentages (range from $2^{22}$ to $8^{14}$ ).

\section{Outcomes and synthesis of results Primary (Exacerbations)}

In FeNO-based adult studies (figure 2), the number of participants with exacerbations in the group with treatment adjusted according to FeNO was similar to the control group; 26 with exacerbations vs 30 , respectively $(p=0.763)$, OR $0.85(95 \% \mathrm{CI}$ 0.30 to 2.43 ). The number of children who had exacerbations in the FeNO-based group was not significantly different in the control group (102 vs 118, respectively, $\mathrm{p}=0.062)$, OR 0.75 (95\% CI 0.55 to 1.01 ) (figure 2 ).

In contrast, in the sputum-based meta-analysis (figure 3) significantly fewer adults in the group that utilised sputum eosinophil count had asthma exacerbations compared with the control group ( 52 vs $77 ; \mathrm{p}=0.0006)$, OR 0.36 (95\% CI 0.20 to 0.64). NNT for benefit was 6 (95\% CI 4-32) over 52 weeks.

\section{Secondary outcomes \\ ICS dose}

For FeNO-based studies, meta-analysis of adult studies was opposite to that of paediatric studies (figure 4). Adults who had treatment adjusted according to FeNO had a significantly lower dose of ICS at the end of the study period (figure 4) than those in the control group (mean difference between groups was $-450.03 \mu$ g budesonide equivalent; $95 \%$ CI -676.73 to -223.34 ; $\mathrm{p}<0.0001)$. However, Shaw ${ }^{19}$ also reported an $11 \%$ increase in the total amount of ICS used during the study $(95 \%$ CI $-15 \%$ to $37 \%$ ). In paediatric studies, the group who had treatment adjusted according to FeNO (figure 4) had significantly higher doses of ICS at the end of the study compared with the control group (mean difference 140.18, 95\% CI 28.94 to 251.42; $\mathrm{p}=0.014$ ).

All three studies that utilised sputum eosinophils to adjust treatment reported no differences in doses of ICS used between groups (figure 5). The SDs for the groups were not available in Jayaram's paper and were estimated based on the data from Green's paper. Mean dose of ICS per person per day between groups was non-significant; weighted mean difference was $78.99,95 \%$ CI -90.13 to $248.11 ; \mathrm{p}=0.157$.

\section{Symptom scores}

Symptom scores did not differ between groups for FeNO-based studies in both adults and children (figure 6). In adults, the mean difference was $-0.10,95 \% \mathrm{CI}-0.33$ to $0.12 ; \mathrm{p}=0.372$. In children, the mean difference was $0.13,95 \%$ CI -0.32 to 0.57 ; $\mathrm{p}=0.577$. For the sputum-based studies, the two studies that reported on symptom scores also described no difference in symptoms scores between groups. ${ }^{14} 15$

\section{Sensitivity analyses}

There were insufficient data reported from the individual studies to include other secondary outcomes (forced expiratory volume in $1 \mathrm{~s}\left(\mathrm{FEV}_{1}\right)$. AHR, rescue $\beta$-agonist use, $\mathrm{QoL}$ ) for meta-analysis. $\mathrm{FEV}_{1}$ was an outcome in all nine studies; eight studies ${ }^{14} 15181921$ described no difference between the participants who had treatment adjusted to inflammatory markers in comparison with the control group.

Results from the sensitivity analyses did not alter direction or non-significance of primary outcomes (exacerbations) but
Figure 5 Mean dose of inhaled corticosteroid per person per day (sputum eosinophils (SpEos)).

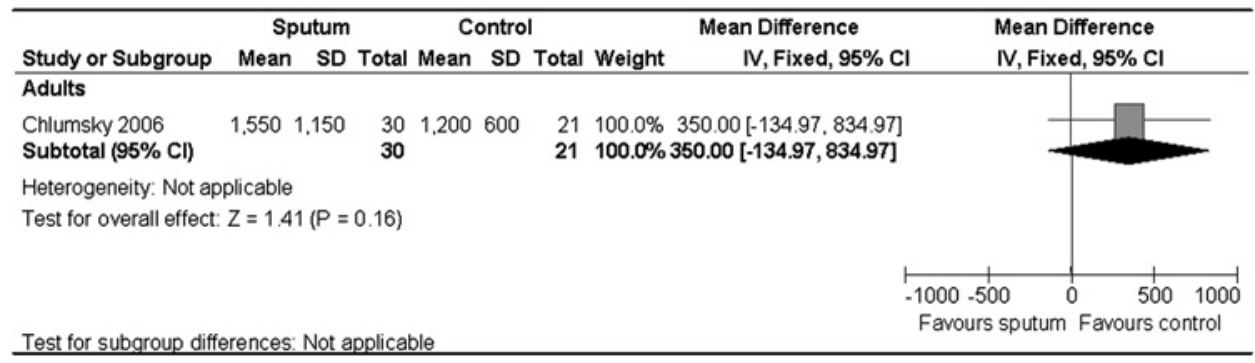


Figure 6 Symptom score (fractional exhaled nitric oxide (FeNO)).

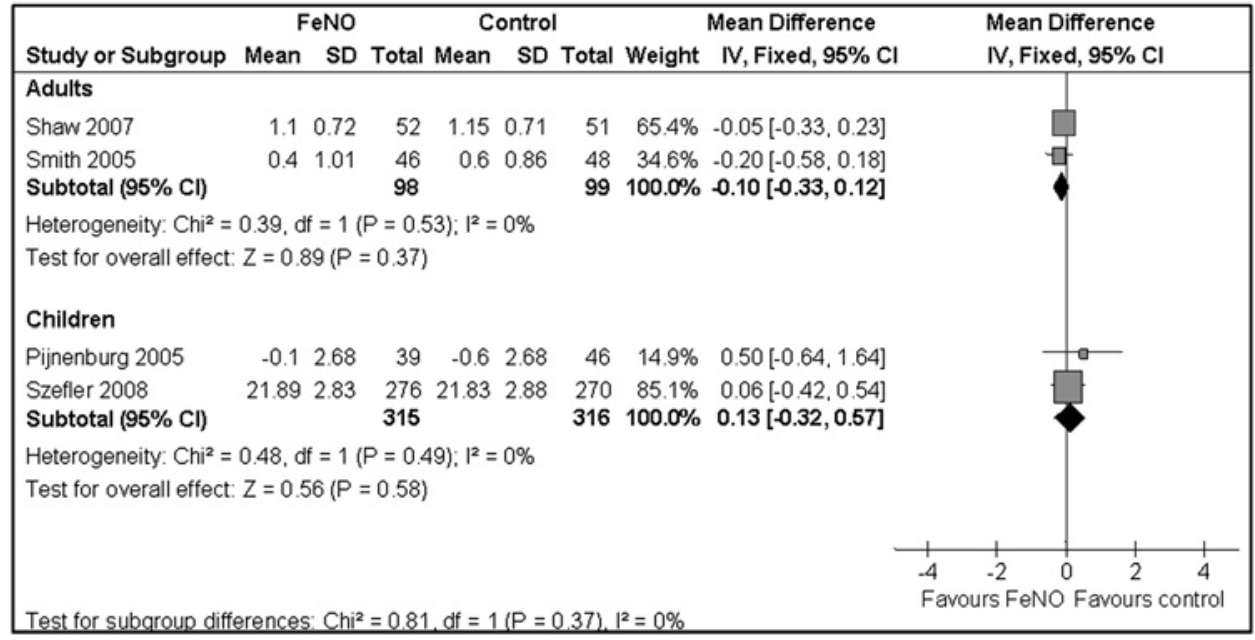

changed the final ICS dose in the paediatric studies from favouring controls to a non-significant difference between groups (see supplementary file online).

\section{Risk of bias in individual studies}

The risk of bias table (table 2) shows that four studies ${ }^{15} 171922$ were considered moderate to high quality, but in all studies there were insufficient details about either allocation concealment

Table 2 Risk of bias summary of included studies

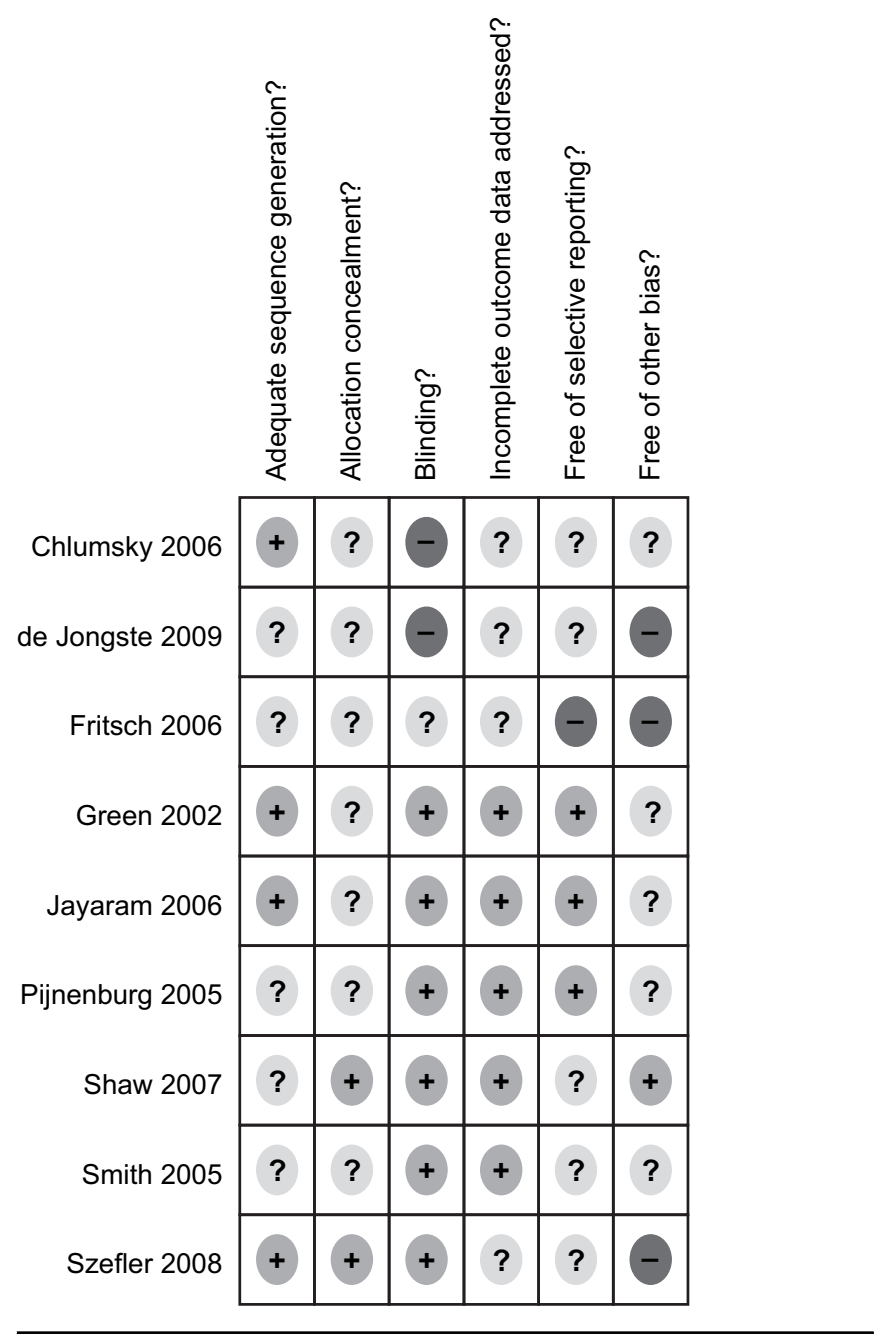

and/or adequacy of blinding. One study ${ }^{14}$ was open labelled while another ${ }^{21}$ was single blinded.

For the FeNO-based papers, the quality of evidence using the GRADE approach surmises that of the four outcomes assessed, three were of moderate quality and one (ICS dose in children) was low quality due to one study ${ }^{21}$ being single blinded and a high final daily dose of ICS in another study ${ }^{20}$ (table 3 ). For sputum-based studies, GRADE assessment shows that the quality of both outcomes was low (exacerbation) and very low (ICS dose) due to the lack of blinding in one study ${ }^{14}$ and the high daily doses of ICS at the end of the study in two studies $^{14} 15$ (table 4).

\section{DISCUSSION}

In this meta-analysis, we combined data from our Cochrane reviews ${ }^{9}{ }^{10}$ that evaluated the efficacy of tailoring asthma interventions based on FeNO or sputum eosinophils in comparison with controls (clinical symptoms with or without spirometry/peak flow) for asthma-related outcomes in children and adults. Based on nine studies in 1299 adults and children (1231 completed), we found that the number of adults who had an exacerbation (as defined by the author) was significantly lower in the group in which ICS was tailored based on sputum eosinophilia compared with the control group (ie, managed with the usual traditional methods, based primarily on clinical symptoms). In contrast there was no significant difference between groups when ICS was tailored based on FeNO. In children/adolescents there was a non-significant trend favouring the FeNO strategy in a number of participants with one or more exacerbations, but this was at the expense of higher levels of ICS. In adults, the FeNO-based strategy enabled a reduction in the final (but not the overall) daily dose of ICS. For both FeNOand sputum-based strategies, there was no difference between groups for all secondary outcomes $\left(\mathrm{FEV}_{1}\right.$, symptom scores, $\mathrm{AHR}$ and $\beta_{2}$-agonist use).

Tailoring medications based on FeNO has been advocated in an editorial ${ }^{23}$ and is now relatively widely used in some countries where a rebate for its use is available. This meta-analysis has shown that the benefits of utilising an FeNO-based strategy (as opposed to a standard strategy based on clinical symptoms and simple tests such as $\mathrm{FEV}_{1}$ ) is at best modest and could potentially be harmful with increased ICS use in children. There was no significant difference between the two strategies in both adult and paediatric studies in the primary outcome of exacerbation when utilising FeNO. The only significant beneficial difference found between groups was the final daily dose of ICS 
Table 3 Grade assessment of FeNO-based papers

\begin{tabular}{|c|c|c|c|c|c|}
\hline \multirow[t]{3}{*}{ Outcomes } & \multicolumn{2}{|c|}{ Illustrative comparative risks* $(95 \% \mathrm{Cl})$} & \multirow{3}{*}{$\begin{array}{l}\text { Relative } \\
\text { effect } \\
(95 \% \mathrm{CI})\end{array}$} & \multirow{3}{*}{$\begin{array}{l}\text { No of } \\
\text { Participants } \\
\text { (studies) }\end{array}$} & \multirow{3}{*}{$\begin{array}{l}\text { Quality of the Comments } \\
\text { evidence } \\
\text { (GRADE) }\end{array}$} \\
\hline & Assumed risk & Corresponding risk & & & \\
\hline & $\begin{array}{l}\text { Intervention based } \\
\text { on clinical symptoms }\end{array}$ & $\begin{array}{l}\text { Tailored intervention } \\
\text { based on FeNO }\end{array}$ & & & \\
\hline $\begin{array}{l}\text { Number of subjects who } \\
\text { had one or more } \\
\text { exacerbations over the } \\
\text { study period in adults } \\
\text { Follow-up: } 52 \text { weeks }\end{array}$ & 30 per 100 & $\begin{array}{l}27 \text { per } 100 \\
(12 \text { to } 51)\end{array}$ & $\begin{array}{l}\text { OR } 0.85 \\
(0.3 \text { to } \\
2.43)\end{array}$ & $\begin{array}{l}197 \\
\text { (2 studies) }\end{array}$ & $\begin{array}{l}\oplus \oplus \oplus \Theta \\
\text { moderate }^{1}\end{array}$ \\
\hline $\begin{array}{l}\text { Number of subjects who } \\
\text { had one or more } \\
\text { exacerbations over the } \\
\text { study period in children } \\
\text { and adolescents } \\
\text { Follow-up: } 26-52 \text { weeks }\end{array}$ & 36 per 100 & $\begin{array}{l}30 \text { per } 100 \\
(24 \text { to } 36)\end{array}$ & $\begin{array}{l}\text { OR } 0.75 \\
(0.55 \text { to } \\
1.01)\end{array}$ & $\begin{array}{l}782 \\
\text { (3 studies) }\end{array}$ & $\begin{array}{l}\oplus \oplus \oplus \ominus \\
\text { moderate }\end{array}$ \\
\hline Follow-up: 52 weeks & $\begin{array}{l}1088 \mathrm{mcg} / \mathrm{day} \\
\text { (budesonide } \\
\text { equivalent) }\end{array}$ & $\begin{array}{l}450 \text { lower } \\
\text { (677 to } 223 \text { lower) }\end{array}$ & & & \\
\hline $\begin{array}{l}\text { ICS dose at final visit in } \\
\text { children and adolescents } \\
\text { mcg/day } \\
\text { Follow-up: } 26-52 \text { weeks }\end{array}$ & $\begin{array}{l}\text { The mean ics dose at } \\
\text { final visit in children } \\
\text { and adolescents in the } \\
\text { control groups was } \\
804 \text { mcg/day } \\
\text { (budesonide } \\
\text { equivalent) }\end{array}$ & $\begin{array}{l}\text { The mean ICS dose at } \\
\text { final visit in children and } \\
\text { adolescents in the } \\
\text { intervention groups was } \\
140 \text { higher } \\
\text { (29 to } 251 \text { higher) }\end{array}$ & & $\begin{array}{l}777 \\
\text { (3 studies) }\end{array}$ & $\begin{array}{l}\oplus \oplus{ }^{\ominus,} \ominus \\
\text { low }^{3,6,7}\end{array}$ \\
\hline
\end{tabular}

GRADE Working Group grades of evidence.

High quality: further research is very unlikely to change our confidence in the estimate of effect.

Moderate quality: further research is likely to have an important impact on our confidence in the estimate of effect and may change the estimate.

Low quality: further research is very likely to have an important impact on our confidence in the estimate of effect and is likely to change the estimate.

Very low quality: we are very uncertain about the estimate.

*The basis for the assumed risk (eg, the median control group risk across studies) is provided in footnotes. The corresponding risk (and its $95 \%$ Cl) is based on the assumed risk in the comparison group and the relative effect of the intervention (and its $95 \% \mathrm{Cl}$ ).

$1 \mathrm{Cls}$ are wide and include clinically important benefit and harm.

2 One study (deJongste 2008) design was open label which may have introduced bias.

3 Studies reported technical difficulties with FeNO analyses as reported in risk of bias table.

4 Medication increased prior to commencement of study.

5 In one study the overall dose of ICS was higher with FeNO-based interventions even though the final ICS dose was lower.

6 One study presented in these results was single blinded with the intervention arm analysing FeNO only.

7 Final ICS doses were quite varied, with one study having particularly high doses.

FeNO, fractional expired nitric oxide; ICS, inhaled corticosteroid.

in adults. However, this finding is limited as this was a post hoc analysis.

The primary outcome chosen was exacerbation, an important outcome as this affects the patient's QoL and the extent to which the patient can carry out their activities of daily life. ${ }^{4}$ Arguably this is the most important outcome in studies on efficacy of interventions for asthma control. Our meta-analysis has shown that in contrast to the non-beneficial effect of FeNO on rate of exacerbation, tailoring treatment based on sputum eosinophils decreased the number of exacerbations experienced by this group of adults.

In contrast to the favourable data in the outcome of exacerbations that support the use of sputum to guide asthma treatments in adults, there was no significant difference between the groups for both sputum- and FeNO-based strategies in other asthma outcomes ( $\mathrm{FEV}_{1}, \mathrm{QoL}$ and $\beta_{2}$-agonist use). While exacerbations are an important outcome, arguably subjective measures of asthma control are also important. Thus, although our findings demonstrate that monitoring airway inflammation through eosinophils in induced sputum is useful in reducing exacerbations, it is debatable whether it should be universally advocated. Furthermore, sputum analysis is restricted to laboratories with specific expertise in inducing and analysing sputum. Obtaining and analysing sputum is relatively time consuming (when compared with FeNO) and is not always successful, particularly in young children. Nevertheless, use of sputum induction to guide asthma treatment is most likely to be beneficial in adults with severe asthma and those with frequent exacerbations.

The FeNO-based studies need to be considered in light of several issues. First, none of the six included studies utilising FeNO considered presence or severity of atopy in their algorithm of management, although some but not all subjects were atopic. Raised FeNO in children has been associated with atopy with or without respiratory symptoms. ${ }^{24}$ Shaw and colleagues ${ }^{19}$ reported that some of their participants were atopic $(62 \%$ in the FeNO group, $70 \%$ in the control group). Smith et al ${ }^{18}$ did not describe whether their subjects were atopic or not. 'Atopic asthma' was an inclusion criterion for Pijnenburg et $a l^{25}$ as 


\begin{tabular}{|c|c|c|c|c|c|c|}
\hline \multirow[t]{3}{*}{ Outcomes } & \multicolumn{2}{|c|}{ Illustrative comparative risks* $(95 \% \mathrm{CI})$} & \multirow{3}{*}{$\begin{array}{l}\text { Relative } \\
\text { effect } \\
(95 \% \mathrm{Cl})\end{array}$} & \multirow{3}{*}{$\begin{array}{l}\text { No of } \\
\text { Participants } \\
\text { (studies) }\end{array}$} & \multirow{3}{*}{$\begin{array}{l}\text { Quality of } \\
\text { the } \\
\text { evidence } \\
\text { (GRADE) }\end{array}$} & \multirow[t]{3}{*}{ Comments } \\
\hline & Assumed risk & Corresponding risk & & & & \\
\hline & $\begin{array}{l}\text { Tailored } \\
\text { interventions } \\
\text { based on clincal } \\
\text { symptoms }\end{array}$ & $\begin{array}{l}\text { Tailored interventions } \\
\text { based on sputum } \\
\text { eosinophils }\end{array}$ & & & & \\
\hline $\begin{array}{l}\text { Number of subjects who } \\
\text { had one or more } \\
\text { exacerbations over the } \\
\text { study period }\end{array}$ & 726 per 1000 & $\begin{array}{l}\mathbf{4 8 8} \text { per } 1000 \\
(346 \text { to } 629)\end{array}$ & $\begin{array}{l}\text { OR } 0.36 \\
(0.2 \text { to } \\
0.64)\end{array}$ & $\begin{array}{l}215 \\
\text { (3 studies) }\end{array}$ & $\begin{array}{l}\oplus \oplus \ominus \ominus \\
\text { low }^{1}\end{array}$ & \\
\hline $\begin{array}{l}\text { Mean dose of inhaled } \\
\text { corticosteroids per } \\
\text { person per day }\end{array}$ & & $\begin{array}{l}\text { The mean Mean dose of } \\
\text { inhaled corticosteroids per } \\
\text { person per day in the } \\
\text { intervention groups was } \\
\mathbf{7 8 . 9 9} \text { higher } \\
\text { (90.13 lower to } 248.11 \\
\text { higher) }\end{array}$ & & $\begin{array}{l}221 \\
\text { (3 studies) }\end{array}$ & $\begin{array}{l}\oplus \ominus \ominus \ominus \\
\text { very low }\end{array}$ & \\
\hline
\end{tabular}

GRADE Working Group grades of evidence.

High quality: further research is very unlikely to change our confidence in the estimate of effect.

Moderate quality: further research is likely to have an important impact on our confidence in the estimate of effect and may change the estimate.

Low quality: further research is very likely to have an important impact on our confidence in the estimate of effect and is likely to change the estimate

Very low quality: we are very uncertain about the estimate.

*The basis for the assumed risk (e.g. the median control group risk across studies) is provided in footnotes. The corresponding risk (and its $95 \%$ Cl) is based on the assumed risk in the comparison group and the relative effect of the intervention (and its $95 \% \mathrm{Cl}$ ).

1 One paper (Chlumsky) was open labelled with no blinding.

2 Two studies (Chlumsky and Green) had significantly higher doses of ICS overall.

ICS, inhaled corticosteroid.

defined as RAST (radioallergosorbent test) class 2 or higher for at least one airborne allergen ever. Similarly, all children in the study of Fritsch et $a l^{16}$ had an inclusion criterion of positive skin prick test or RAST.

Secondly, the cut-offs of FeNO utilised for stepping up or down treatment differed between studies (range 15-30 ppb). The subjects of the study of Pijnenburg et al ${ }^{17}$ (paediatric study) had the highest mean daily dose of ICS and subjects in this study also had quite high FeNO at the final visit ( $\sim 25.5 \mathrm{pbb}$ in the FeNO group, 36.7 in the controls). Disconcertingly, use of the FeNO strategy did not result in a lower FeNO level at the end of the trial. Smith et $a l^{18}$ mentioned that their $15 \mathrm{ppb}$ threshold is equivalent to $35 \mathrm{ppb}$ at a slower $50 \mathrm{ml} / \mathrm{s}$ flow rate. There is no evidence-based algorithm to adjust treatment in relation to FeNO levels (or indeed to sputum eosinophils levels). There are differences in guidelines (such as GINA ${ }^{1}, \mathrm{BTS}^{2}, \mathrm{NAC}^{3}$ ) with respect to when and how to step-up and step-down asthma treatments. Arguably the algorithm should provide a result sufficiently different from clinical decision making in order for there to be any benefit. ${ }^{26}$

The difference in results of using sputum eosinophils (beneficial for exacerbations) versus FeNO (not beneficial) is likely to be because FeNO levels do not necessarily reflect sputum eosinophil density, particularly in non-steroid-naïve patients. ${ }^{27} 28$ Also, consideration of cost is important for the universal use of $\mathrm{FeNO}$ in health systems. FeNO measurements require a nitric oxide analyser that needs maintenance and/or calibration. Nitric oxide analysers are relatively expensive, and adding FeNO as a monitoring tool adds not only cost but also another layer of complexity in asthma care. Analysers were only approved by the US Food and Drug Administration for clinical monitoring of anti-inflammatory treatment in $2003 .{ }^{29}$ As reported in the risk of bias table (table 2), accurate FeNO measurements at each visit could not be obtained, due either to a faulty analyser ${ }^{21}$ or to technical issues. ${ }^{16}$ Also, many aspects need to be considered when analysing FeNO; this includes the timing of spirometry (transiently reduces FeNO), food and beverage, circadian rhythm, smoking history, ambient nitric oxide and exercise. ${ }^{29}$

\section{Limitations of the review}

This systematic review is limited to nine studies with 1231 subjects completing the trials. While the studies share some common issues, there are also significant differences, notably the definition of asthma exacerbation, how the decision to prescribe oral steroids was made, the different cut-off levels for FeNO and sputum eosinophils, the control strategies and how medications were adjusted.

Sensitivity analyses was done post hoc where the study of Szefler et $a l^{20}$ was excluded from the meta-analysis, as study design was slightly different because traditional asthma measures were part of both groups. While the non-significant difference between groups for the primary outcome was upheld, that for the final ICS that favoured controls became non-significant.

\section{CONCLUSION}

The studies included in this review highlight the difficulties involved in tailoring the dose of ICS based on inflammatory markers (FeNO and sputum eosinophils), instead of primarily on clinical symptoms. Tailoring of asthma treatment based on sputum is effective in decreasing asthma exacerbations in adults. However, tailoring of asthma treatment based on FeNO levels has not been shown to be effective in improving asthma outcomes in children and adults. At present, despite their popularity, there is insufficient evidence to advocate their use in routine clinical practice. 
Further randomised controlled trials in both adults and children are required. A priori pragmatic issues of clinical practice such as high versus low doses of ICS and, to a lesser extent, eosinophilic versus non-eosinophilic asthma should be considered with costs analysis for each subgroup. Future randomised controlled trials should preferably be parallel multicentre studies and include outcomes of exacerbations, subjective measures (such as scores for asthma control and QoL) as well as objective measures $\left(\mathrm{FEV}_{1}\right.$, etc.). It is likely that a clear algorithm based on outcomes rather than a single cut-off is required. ${ }^{26}$ Analysis of costs and possible adverse events of inhaled and oral corticosteroids would also provide additional important information.

Funding Australian Cochrane Airways Group and Royal Children's Hospital Foundation. AC is supported by an NHMRC Practitioner Fellowship (grant no. 545216).

Competing interests None.

Provenance and peer review Not commissioned; externally peer reviewed.

\section{REFERENCES}

1. GINA Report, Global Strategy for Asthma Management and Prevention, 2008. http://www.ginasthma.com/GuidelinesResources.asp (accesssed Nov 2009).

2. Asthma Management Handbook. Australia, Melbourne: National Asthma Council, 2006. http://www.nationalasthma.org.au/cms/index.php (accessed Nov 2009).

3. British Thoracic Society Scottish Intercollegiate Guidelines Network. British guideline on the management of asthma. Thorax 2008;63(Suppl 4:iv): $1-121$.

4. Reddel HK, Taylor DR, Bateman ED, et al. An official American Thoracic Society/ European Respiratory Society statement: asthma control and exacerbations; standardizing endpoints for clinical asthma trials and clinical practice. Am J Respir Crit Care Med 2009;180:59-99.

5. Zacharasiewicz A, Wilson N, Lex C, et al. Clinical use of noninvasive measurements of airway inflammation in steroid reduction in children. Am J Respir Crit Care Med 2005;171:1077-82.

6. Douwes J, Gibson P, Pekkanen J, et al. Non-eosinophilic asthma: importance and possible mechanisms. Thorax 2002;57:643-8.

7. Berry M, Morgan A, Shaw D, et al. Pathological features and inhaled corticosteroid response of eosinophilic and non-eosinophilic asthma. Thorax 2007;62:1043-9.

8. Wark PA, Gibson PG. Clinical usefulness of inflammatory markers in asthma. Am J Respir Med 2003;2:11-19.

9. Petsky H, Kynaston J, Turner C, et al. Tailored interventions based on sputum eosinophils versus clinical symptoms for asthma in children and adults. Cochrane Database Syst Rev 2007;(2):CD005603.

10. Petsky HL, Cates CJ, Li AM, et al. Tailored interventions based on exhaled nitric oxide versus clinical symptoms for asthma in children and adults. Cochrane Database Syst Rev 2009;(2):CD006340.
11. Liberati A, Altman DG, Tetzlaff J, et al. The PRISMA statement for reporting systematic reviews and meta-analyses of studies that evaluate healthcare interventions: explanation and elaboration. $\mathrm{Br}$ Med J 2009;339:b2700.

12. Visual Rx. Online NNT calculator [program]. 3 version, 2008.

13. Higgins JP, Green S, eds. Analysing and Presenting Results. Chichester, UK: John Wiley \& Sons Ltd, updated, M2005.

14. Chlumsky J, Striz I, Terl M, et al. Strategy aimed at reduction of sputum eosinophils decreases exacerbation rate in patients with asthma. J Int Med Res 2006:34:129-39.

15. Green RH, Brightling CE, McKenna S, et al. Asthma exacerbations and sputum eosinophil counts: a randomised controlled trial. Lancet 2002;360:1715-21.

16. Fritsch M, Uxa S, Horak F Jr, et al. Exhaled nitric oxide in the management of childhood asthma: a prospective 6-months study. Pediatr Pulmonol 2006;41:855-62.

17. Pijnenburg M, Bakker E, Hop W, et al. Titrating steriods on exhaled nitric oxide in children with asthma: a randomised controlled trial. Am J Respir Crit Care Med 2005; 172:831-6

18. Smith AD, Cowan JO, Brassett KP, et al. Use of exhaled nitric oxide measurements to guide treatment in chronic asthma. N Engl J Med 2005;352:2163-73.

19. Shaw D, Perry MA, Thomas M, et al. The use of exhaled nitric oxide to guide asthma management. Am J Respir Crit Care Med 2007:176:231-7.

20. Szefler SJ, Mitchell H, Sorkness CA, et al. Management of asthma based on exhaled nitric oxide in addition to guideline-based treatment for inner-city adolescents and young adults: a randomised controlled trial. Lancet 2008; 372:1065-72.

21. de Jongste JC, Carraro S, Hop WC, et al. Daily telemonitoring of exhaled nitric oxide and symptoms in the treatment of childhood asthma. Am J Respir Crit Care Med 2009;179:93-7.

22. Jayaram L, Pizzichini MM, Cook RJ, et al. Determining asthma treatment by monitoring sputum cell counts: effect on exacerbations. Eur Respir $J$ 2006;27:483-94

23. Szefler S. Facing the challenges of childhood asthma: what changes are necessary? J Allergy Clin Immunol 2005;115:685-8.

24. Franklin PJ, Turner SW, Le Souef PN, et al. Exhaled nitric oxide and asthma: complex interactions between atopy, airway responsiveness, and symptoms in a community population of children. Thorax 2003;58:1048-52.

25. Pijnenburg M, Hofhuis W, Hop W, et al. Exhaled nitric oxide predicts asthma relapse in children with clinical asthma remission. Thorax 2004;60:215-18.

26. Gibson PG. Using fractional exhaled nitric oxide to guide asthma therapy: design and methodlogical issues for ASthma ALgorithm studies. Clin Exp Allergy 2009; 39:478-90

27. Leuppi JD, Salome CM, Jenkins CR, et al. Markers of airway inflammation and airway hyperresponsiveness in patients with well-controlled asthma. Eur Respir $J$ 2001; 18:444-50

28. Lim S, Jatakanon A, John M, et al. Effect of inhaled budesonide on lung function and airway inflammation. Assessment by various inflammatory markers in mild asthma. Am J Respir Crit Care Med 1999;159:22-30.

29. American Thoracic Society. ATS/ERS recommendations for standardized procedures for the online and offline measurement of exhaled lower respiratory nitric oxide and nasal nitric oxide, 2005. Am J Respir Crit Care Med 2005:171:912-30. 